\title{
Postoperative immunological response against contractile proteins after coronary bypass surgery
}

\author{
IVAN DE SCHEERDER, * MARC DE BUYZERE, * JOHAN ROBBRECHT, $\dagger$ \\ MARIJKE DE LANGE, * JORIS DELANGHE, $\dagger$ ANNE MARIE BOGAERT, * \\ DENIS CLEMENT*
}

From the ${ }^{\star D e p a r t m e n t s ~ o f ~ C a r d i o l o g y ~ a n d ~} \dagger$ Clinical Chemistry, University Hospital, Ghent, Belgium

SUMMARY The pathogenesis of post-cardiac injury syndromie was studied prospectively in 62 patients who underwent coronary bypass grafting. Preoperative and serial postoperative titres of actin and myosin antibodies were measured by an enzyme linked immunosorbent assay. Perioperative cumulative release of serum aspartate and alanine aminotransferases, lactate dehydrogenase, and creatine kinase was calculated by approximation formulas that are used to estimate infarct size. Complete post-cardiac injury syndrome developed in eight $(13 \%)$ patients and an incomplete syndrome developed in $16(26 \%)$. There was a significant correlation between frequency and intensity of the syndrome and the ratio of postoperative to preoperative titres of actin and myosin antibodies. Furthermore, there was a significant correlation between the cumulative release of lactate dehydrogenase, serum aspartate aminotransferase, and creatine kinase and the number of coronary vessels that were grafted, but no correlation was found between the incidence of post-cardiac injury syndrome and the number of coronary bypasses grafted or between the cumulative enzyme release and the postoperative immunological response against the major contractile proteins, actin and myosin. The amount of enzymes released during coronary bypass surgery seems to be a good indicator of the extent of myocardial damage during operation but it does not determine either the incidence of post-cardiac injury syndrome or the postoperative immunological response against the main contractile proteins actin and myosin.

Post-cardiac injury syndrome is a frequent complication of cardiac surgery ${ }^{1-7}$; it is seen less often after acute myocardial infarction, ${ }^{78}$ despite the generally more severe myocardial damage produced by infarction. Furthermore, post-cardiac injury syndrome was found to be significantly more frequent after valve replacement surgery than after coronary bypass operation. ${ }^{69}$ According to Engle et al more severe myocardial damage after valve replacement explains this observation. ${ }^{9}$ Aortic valve replacement gives rise to a greater cumulative enzyme release of creatine kinase, creatine kinase $\mathrm{MB}$, and $\alpha$ hydroxybutyrate dehydrogenase than coronary artery bypass grafting which in turn gives rise to greater cumulative enzyme release than mitral valve replacement. ${ }^{1011}$ Thus the reason for the significantly

Requests for reprints to Dr Ivan De Scheerder, Department of Cardiology, University Hospital, De Pintelaan 185, B-9000 Ghent, Belgium.

Accepted for publication 2 June 1986 higher frequency of post-cardiac injury syndrome after valve replacement surgery than after coronary artery bypass grafting remains controversial. De Scheerder et al demonstrated that the difference in occurrence of post-cardiac injury syndrome after cardiac surgery and acute myocardial infarction correlated well with the difference of post-cardiac injury humoral immune response against myocardial tissue and the major contractile proteins, actin and myosin, ${ }^{7}$ suggesting that this immune response is important in the pathogenesis of postcardiac injury syndrome.

We have studied the correlation between the tissue damage during coronary artery bypass grafting, estimated by calculation of the cumulative enzyme release, and the postoperative immune response against the contractile proteins.

\section{Patients and methods}

PATIENTS

We studied 62 patients ( 10 women and 52 men, aged 
45-72 years (mean 53)) who underwent coronary aortic bypass grafting for chronic ischaemic heart disease during a nine month period. The numbers of patients and vessels grafted was as follows: 8 patients, 1 graft; 10 patients, 2 grafts; 20 patients, 3 grafts; 15 patients, 4 grafts; 7 patients, 5 grafts; 1 patient, 6 grafts; and one patient, 7 grafts.

\section{CUMULATIVE ENZYME RELEASE}

Serum samples for measurement of cumulative enzyme release were collected every eight hours during the first $\mathbf{7 2}$ hours postoperatively and then every day during the next week. Enzymes (serum aspartate and alanine aminotransferases, lactate dehydrogenase, and creatine kinase) were determined immediately after centrifugation. Serum aspartate and alanine aminotransferases, and lactate dehydrogenase were assayed by methods described by the German Clinical Chemistry Society (1970) by means of test kits (Boehringer, 258784, 258822, and 543039 respectively). Creatine kinase was assayed by means of a creatine kinase $\mathrm{N}$-acetyl cysteine activated method (Boehringer test kit 475734) described by Szasz et al. ${ }^{12}$ Cumulative enzyme release during operation was estimated from the approximation formulas that are used to calculate the area under the curve of the enzyme activity as a function of time from the start of the operation until the return to normal concentrations. A period of $24 \mathrm{~h}$ was taken as an arbitrary unit on the $\mathrm{X}$ axis and enzyme release was calculated as described by Roberts et al. ${ }^{13}$

\section{IMMUNOLOGICAL RESPONSE TO ACTIN AND MYOSIN}

Serum samples for the detection of actin and myosin antibodies were collected before operation and from 1 to 60 days postoperatively. Serum samples were stored at $-20^{\circ} \mathrm{C}$ and analysed blindly within 10 months.

The indirect enzyme linked immunosorbent assay was used to measure actin and myosin autoantibodies. ${ }^{14}$ Rabbit muscle heavy meromyosin $(200 \mu \mathrm{g} / \mathrm{ml}){ }^{\circ}$ (Sigma) and bovine cardiac actin $(200 \mu \mathrm{g} / \mathrm{ml})$, prepared according to Spudich and Watt, ${ }^{15}$ were coated overnight at $4^{\circ} \mathrm{C}$ on to glutaraldehyde coated immunobeads (Plastic Ball Company) in phosphate buffered saline solution $(0 \cdot 15 \mathrm{~mol} / 1, \mathrm{pH} 7 \cdot 2)$. Sera were added in a $1 / 250$ dilution in the phosphate buffer and incubated at $37^{\circ} \mathrm{C}$ for $2 \mathrm{~h}$. After washing with phosphate buffer/Tween $200.05 \% /$ gelatine $0.25 \%$, alkaline phosphatase conjugated goat polyclonal antihuman IgG (Sigma) was added in a dilution of $1 / 1000$ and incubated at $37^{\circ} \mathrm{C}$ for $2 \mathrm{~h}$. After washing, the activity of the bound enzyme was measured in an assay with p-nitrophenylphosphate disodium (Sigma) as sub- strate. The reaction was stopped by the addition of $1 \mathrm{~mol} / \mathrm{l}$ of sodium hydroxide. The absorbance was measured on a Vitatron spectrophotometer at a wavelength of $410 \mathrm{~nm}$. The postoperative immunological response was calculated from the postoperative:preoperative ratio of actin and myosin antibodies (IgG).

STATISTICS

The correlation between the clinical classification of post-cardiac injury syndrome and the postoperative immunological response was calculated by means of the Kruskal-Wallis analysis, and the correlation between the clinical classification post-cardiac injury syndrome and the number of coronary bypasses grafted was calculated by the $\chi^{2}$ test. We used regression analysis to determine the correlation between cumulative enzyme release, the number of coronary bypasses grafted, and the postoperative immunological response.

\section{Results}

POST-CARDIAC INJURY SYNDROME

The 62 patients were divided into three groups according to their clinical features. Group 1 consis-

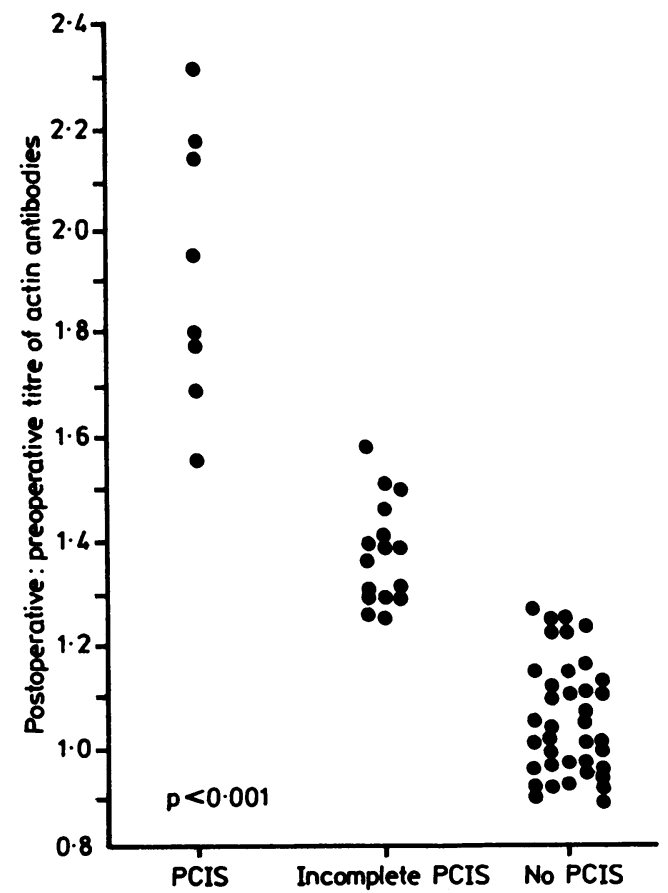

Fig 1 Correlation between the clinical classification of the post-cardiac injury syndrome (PCIS) and the ratio of postoperative to preoperative titres of actin antibody. $P$ value was calculated by Kruskal-Wallis one way analysis of variance by ranks. 
Table 1 Correlation between the clinical classification of post-cardiac injury syndrome (PCIS) and the number of coronary bypasses grafted

\begin{tabular}{lccl}
\hline No of grafts & No PCIS & Incomplete PCIS & PCIS \\
\hline 1 & 4 & 3 & 1 \\
2 & 5 & 3 & 2 \\
3 & 14 & 4 & 2 \\
4 & 9 & 4 & 2 \\
5 & 5 & 1 & 1 \\
6 & 0 & 1 & 0 \\
7 & 1 & 0 & 0 \\
Total & 38 & 16 & 8 \\
\hline
\end{tabular}

$\chi^{2}$ value for comparison incidence of post-cardiac injury syndrome in each coronary bypass operation group is $5.902(\mathrm{p}=0.920)$.

tures of post-cardiac injury syndrome after the first postoperative week, that is fever, pericarditis, and laboratory evidence of inflammation. Group 2 was made up of 16 patients who showed two of the main features (incomplete syndrome), and group 3 was made up of 38 patients who fulfilled one or none of the main features (no syndrome).

Figures 1 and 2 show that there was significant direct correlation between the intensity of postcardiac injury syndrome and the postoperative immunological response against actin and myosin. There was no significant correlation between the frequency and intensity of post-cardiac injury syndrome and the number of coronary arteries grafted (table 1).

Table 2 shows that there was a significant correlation between the number of coronary arteries grafted and the cumulative release of serum aspartate aminotransferase $(p<0.05)$, lactate dehydrogenase $(p<0.03)$, and creatine kinase $(p<0.05)$, but not of serum alanine aminotransferase. The cumulative release of heart specific (MB) creatine kinase was not measured after bypass surgery because we considered only the variables associated with total tissue damage. There was no significant correlation between cumulative enzyme release and

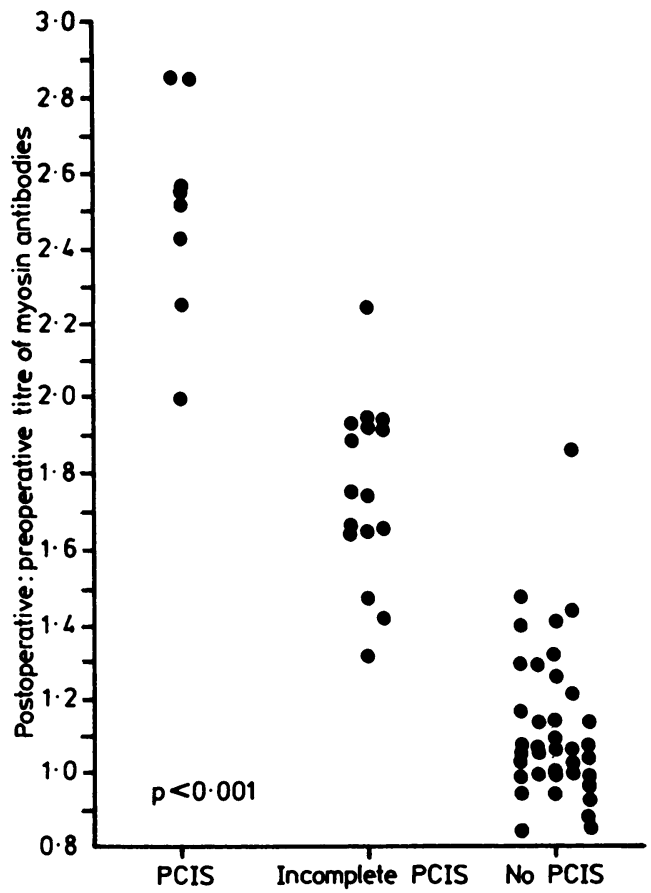

Fig 2 Correlation between the clinical classification of the post-cardiac injury syndrome (PCIS) and the ratio of postoperative to preoperative titres of myosin antibody. P value was calculated by Kruskal-Wallis one way analysis of variance by ranks.

postoperative concentrations of actin and myosin antibodies.

\section{Discussion}

Post-pericardiotomy syndrome is characterised by the persistence after the first postoperative week of fever, leucocytosis, and signs of pericardial and often pleural reaction, frequently with effusion and pneumonitis. ${ }^{45}$ A similar illness, post-myocardial infarction syndrome, was first described by Dressler

Table 2 Correlation between the number of coronary bypasses grafted and the cumulative enzyme release (mean (range))

\begin{tabular}{|c|c|c|c|c|c|}
\hline & No of cases & $A S T(U / l)$ & $A L T(U / l)$ & $L D H(U / l)$ & $C K(U / l)$ \\
\hline $\begin{array}{l}1 \\
2 \\
3 \\
4 \\
5 \\
6 \\
7\end{array}$ & $\begin{array}{r}8 \\
10 \\
20 \\
15 \\
7 \\
1 \\
1\end{array}$ & $\begin{array}{l}142(91-231) \\
162(99-224) \\
196(136-283) \\
229(123-325) \\
348(179-725) \\
386 \\
312 \\
p=0.049\end{array}$ & $\begin{array}{l}99(70-130) \\
99(68-134) \\
124(72-342) \\
116(52-146) \\
134(81-174) \\
183 \\
134 \\
p=0.288\end{array}$ & $\begin{array}{l}1096(782-1687) \\
1380(1130-2036) \\
1594(1192-1928) \\
1963(1279-2133) \\
2148(1270-4426) \\
2267 \\
2253 \\
p=0.028\end{array}$ & $\begin{array}{l}1573(1138-2742) \\
1863(1084-2632) \\
2283(1058-3145) \\
2924(1504-4294) \\
3672(2404-13068) \\
4006 \\
3874 \\
p=0.046\end{array}$ \\
\hline
\end{tabular}

$p$ values by regression analysis.

AST, aspartate aminotransferase; ALT, alanine aminotransferase; LDH, lactate dehydrogenase; CK, creatine kinase. 
et al. ${ }^{16-18}$ The prevalence after acute myocardial infarction varies from $0 \%$ to $6 \%$ in different studies. ${ }^{819-24}$ Because other forms of cardiac injury also give rise to a similar complication, this syndrome is now generally called post-cardiac injury syndrome. ${ }^{25}$

Although these syndromes are strikingly similar and have been well defined clinically, their pathogenesis remains unclear. Soloff et al initially described post-cardiac injury syndrome after mitral commissurotomy. ${ }^{26}$ The cause was originally thought to be a reactivation of rheumatic fever. Subsequently, however, the syndrome was reported after various operations in which the pericardium was entered, and the name postpericardiotomy syndrome was suggested by Ito et al. ${ }^{27}$ They suggested hypersensitivity to blood in the pericardial cavity as the pathogenic mechanism. In children and adults Engle et al found significant correlations between the development of post-cardiac injury syndrome and high titres of heart antibodies and a rise in the titres of antibodies to one or more viruses that were prevalent in the community. ${ }^{49}$ Furthermore, they found significant correlations between the incidence of post-cardiac injury syndrome, heart antibodies, and the type of operation. After heart operation in children Engle et al found that post-cardiac injury syndrome was most common in those operated on because of tetralogy of Fallot and ventricular septum defect with other anomalies. ${ }^{28}$ The potential for myocardial trauma during both these operations is high because they entail a right ventriculotomy and resection of obstructing musculature in the outflow tract of the right ventricle.

In adults post-cardiac injury syndrome occurred less often after coronary artery bypass grafting than after cardiac surgery for valve replacement. ${ }^{9}$ Again it was thought that there was more opportunity for damage to the heart muscle when the aortic valve, mitral valve, or both valves were replaced than after grafting of the coronary arteries on the surface of the heart.

In conclusion, the incidence of post-cardiac injury syndrome was correlated with the magnitude of heart injury during operation. De Scheerder et al also found that post-cardiac injury syndrome was more common after valve replacement operation than after coronary artery bypass grafting ${ }^{6}{ }^{7}$ but they demonstrated a significantly higher frequency of post-cardiac injury syndrome after cardiotomy than after acute myocardial infarction despite the fact that acute myocardial infarction generally causes greater myocardial damage. These clinical results accord with the immunological reaction against heart muscle and the major contractile proteins, which was significantly more important after cardiac surgery than after acute myocardial infarction; there was a clear correlation between the clinical intensity of post-cardiac injury syndrome and the titres of specific autoantibodies against actin and myosin.

We found no correlation between the number of coronary arteries grafted and the degree of postcardiac injury syndrome. Nor was there a significant correlation between the cumulative enzyme release after coronary bypass operation and the postoperative immunological response against the major contractile proteins, actin and myosin. Although there were considerable individual differences in cumulative enzyme release after coronary bypass surgery, a significant correlation between the cumulative enzyme release and the number of coronary arteries grafted was demonstrated in our study. Cumulative enzyme release as calculated in our study is not entirely determined by the amount of enzymes leaking from the affected area of the heart into the circulation; other tissue damage during operation may be involved.

The humoral immunological response to actin and myosin is also triggered by contractile proteins from all sources. Tissue damage causing the release of enzymes and contractile proteins originates mainly in myocardium tissue, however, and other sources are unlikely to have affected the results of this study to a great extent. Our results strongly suggest that the amount of enzyme release during coronary bypass surgery, which is a good indicator of myocardial damage during the operation, does not determine the frequency of post-cardiac injury syndrome after coronary bypass surgery nor does it determine postoperative humoral immune response.

Other exogenous factors may influence the postoperative immune response and the occurrence of post-cardiac injury syndrome. These include concurrent viral infection which may trigger immune response, ${ }^{4}$ exposure to air or to chemicals (disinfectants) which may denature a fraction of the released proteins so that they become more immunogenic than the native molecules, or the action of anaesthetic agents which may change immune response and the way in which antigens are presented to the immune system.

Other, and possibly more important, intrinsic factors influencing individual immune response should also be investigated so that the postoperative immune responses and the pathogenesis of postcardiac injury syndrome may be better understood.

I De $\mathrm{S}$ is a research associate of the Belgian National Fund for Scientific Research (NFWO). This research was supported in part by the Belgian National Fund for Scientific Research (NFWO). 


\section{References}

1 Engle MA, Ito T. The post pericardiotomy syndrome. Am $\mathcal{f}$ Cardiol 1961;7:73-82.

2 McCabe JC, Ebert PA, Engle MA, Zabriskie JB. Circulating heart-reactive antibodies in the post pericardiotomy syndrome. $\mathcal{F}$ Surg Res 1973;14:158-64.

3 Engle PA, McCabe JC, Ebert PA, Zabriskie JB. The post pericardiotomy syndrome and antiheart antibodies. Circulation 1974;49:401-6.

4 Engle MA, Zabriskie JB, Senterfit LB, Tay DJ, Ebert PA. Immunologic and virologic studies in the postpericardiotomy syndrome. $\mathcal{F}$ Pediatr $1975 ; 87: 1103-8$.

5 Maisch B, Berg PA, Kocksiek K. Clinical significance of immunopathological findings in patients with post-pericardiotomy syndrome. I: Relevance of antibody pattern. Clin Exp Immunol 1979;38:189-97.

6 De Scheeder I, Wulfrank D, Van Renterghem L, et al. Association of anti-heart antibodies and circulating immune complexes in the post-pericardiotomy syndrome. Clin Exp Immunol 1984;57:423-8.

7 De Scheerder I, Vandekerckhove J, Robbrecht J, et al . The post-cardiac injury syndrome and an increased humoral immune response against the major contractile proteins (actin and myosin). Am $\mathcal{f}$ Cardiol 1985;56:631-3.

8 Welin L, Vedin A, Wilhelmsson C. Characteristics, prevalence, and prognosis of postmyocardial infarction syndrome. Br Heart $\mathcal{f}$ 1983;50:140-5.

9 Engle MA, Gay WA Jr, McCabe JC, et al. Post pericardiotomy syndrome in adults: incidence, autoimmunity and virology. Circulation 1981;64(suppl II):58-60.

10 Van der Laarse A, Davids HA, Hollaar L, Van der Valk EJM, Witteveen SA, Hermens WT. Recognition and quantification of myocardial injury by means of plasma enzyme and isoenzyme activities after cardiac surgery. Br Heart $\mathcal{f}$ 1979;41:660-7.

11 Davids HA, Hermens WT, Hollaar L, Van der Laarse A, Huysmans HA. Extent of myocardial damage after open-heart surgery assessed from serial plasma enzyme levels in either of two periods (1975 and 1980). Br Heart $\mathcal{F}$ 1982;47:167-72.

12 Szasz G, Gruber W, Bernt E. Creatine kinase in serum: 1. Determination of optimum reaction conditions. Clin Chem 1976;22:650-6.

13 Roberts R, Henry PD, Sobel BE. An improved basis for enzymatic estimation of infarct size. Circulation 1975;52:743-54.
14 Voller A, Bartlett A, Bidwell DE. Enzyme immunoassay with special reference to ELISA techniques. f Clin Path 1978;31:507-20.

15 Spudich J, Watt $S$. The regulation of rabbit skeletal muscle contraction. I. Biochemical studies of the interaction of the tropomyosine-troponin complex with actin and the proteolytic fragments of myosin. f Biol Chem 1971;246:4866-71.

16 Dressler W. Post-myocardial infarction syndrome: preliminary report of complication resembling idiopathic, recurrent benign pericarditis. $\mathscr{f} A M A$ 1956;160:1379-83.

17 Dressler W. Post-myocardial infarction syndrome: report on forty-four cases. Arch Intern Med 1959;103:28-42.

18 Dressler W, Yurkorfsky J, Starr MC. Hemorrhagic pericarditis, pleurisy and pneumonia complicating recent myocardial infarction. Am Heart f 1957; 54:42-9.

19 Weiser NJ, Kantor M, Russell HK. Postmyocardial infarction syndrome. Circulation 1959;20:371-80.

20 Davidson C, Oliver MF, Robertson RF. Postmyocardial-infarction syndrome. $\mathrm{Br} \mathrm{Med} \mathcal{F} 1961$; ii:535-9.

21 Thadani U, Chopra MP, Aber CP, Portal RW. Pericarditis after acute myocardial infarction. $\mathrm{Br} \mathrm{Med} \mathcal{F}$ 1971;ii:135-7.

22 Kossowsky WA, Lyon AF, Spain DM. Reappraisal of the post-myocardial infarction Dressler's syndrome. Am Heart $\mathcal{F} 1981$;102:954-6.

23 Lichtein $\mathrm{E}$. The changing spectrum of post-myocardial infarction pericarditis. Int $\mathcal{F}$ Cardiol 1983;4:234-7.

24 Northcote JR, Hutchison SJ, McGuinness JB. Evidence for the continued existence of the postmyocardial infarction (Dressler's) syndrome. Am $\mathfrak{F}$ Cardiol 1984;53:1201-2.

25 Stelzner TJ, King TE Jr, Antony VB, Sahn SA. The pleuro-pulmonary manifestations of the postcardiac injury syndrome. Chest 1983;4:383-7.

26 Soloff LA, Zatuchni J, Janton H, O'Neill TJE, Glover RP. Reactivation of rheumatic fever following mitral commissurotomy. Circulation 1953;7:481-93.

27 Ito T, Engle MA, Goldberg HP. Post-pericardiotomy syndrome following surgery for nonrheumatic heart disease. Circulation 1958;17:549-56.

28 Engle MA, Zabriskie JB, Senterfit LB, Gay WA Jr, O'Loughlin JE, Ehlers KH. Viral illness and the postpericardiotomy syndrome. A prospective study in children. Circulation 1980;62:1151-8. 